\title{
Histoire sociale et intellectuelle de la Chine,
} 1975-1992

Jacques Gernet

\section{(2) OpenEdition \\ Journals}

Édition électronique

URL : https://journals.openedition.org/annuaire-cdf/1075

DOI : 10.4000/annuaire-cdf. 1075

ISBN : 978-2-7226-0325-7

ISSN : 2109-9227

Éditeur

Collège de France

Édition imprimée

Date de publication : 1 avril 2013

Pagination : 796

ISBN : 978-2-7226-0198-7

ISSN : 0069-5580

\section{Référence électronique}

Jacques Gernet, « Histoire sociale et intellectuelle de la Chine, 1975-1992 », L'annuaire du Collège de

France [En ligne], 112 | 2013, mis en ligne le 22 novembre 2013, consulté le 22 août 2022. URL : http:// journals.openedition.org/annuaire-cdf/1075; DOI : https://doi.org/10.4000/annuaire-cdf.1075 
12 au 26 mai 2012 : mission à Caboul en compagnie d'Éric Ollivier, sous les auspices de la Délégation archéologique française en Afghanistan, pour étude des monuments bouddhiques en cours de fouille (Tepe Narenj et Mes Aynak) et conférences à l'université.

M. Jacques GERNET, membre de l'Institut

(Académie des inscriptions et belles-lettres)

Histoire sociale et intellectuelle de la Chine, 1975-1992

\section{PUBLICATIONS}

Gernet J., Die Begegnung Chinas mit dem Christentum, Monumenta Serica, Monograph Series XLII, Sankt Augustin, 2012, 413 p.

Gernet J., « Astronomie et calendrier. Sur un livre récent de J.-C. Martzloff », T'oung Pao, Revue internationale de sinologie, vol. XCVII, fasc. 4-5, 2011, 371-392.

M. Jean GUILAINE, membre de l'Institut

(Académie des inscriptions et belles-lettres)

\section{Civilisations de l'Europe au Néolithique et à l'Âge du bronze, 1994-2007}

\section{PuBlicATIONS}

\section{Ouvrages}

Guilaine J., Archéologie, science humaine, entretiens avec Anne Lehoërff, Actes-Sud/ Errance, 2011, 240 p.

Guilaine J., Méditerranée mégalithique. Dolmens, hypogées, sanctuaires, LacapelleMarival, Éditions Archéologie nouvelle, Col. «Archéologie vivante », 2011, 157 p., 217 fig.

\section{Articles}

Guilaine J., «Le Prédynastique vu de la Méditerranée », Archéo-Nil, 20, décembre 2010, Cybèle, 17-24.

Guilaine J., «Megalitos de Francia : distribución geográfica y cronologia / Megaliths in France: geographical distribution and chronology » in Scarre C., Garcia-Sanjuan L. et Weatley D.-W. (dir.), Exploring time and matter in prehistoric monuments: debating absolute chronology and rare rocks in European megaliths, Menga, Serie Monografica, 01, Antequera, 2011, 76-101. 